\title{
APPLICATION OF INTEGRATED PROGRAMME/RESOURCE MANAGEMENT SYSTEMS FOR MAJOR CONSTRUCTION PROJECTS
}

\author{
Zhang Wei \\ Planning Engineer, Maunsell Management Consultant Ltd, Hong Kong
}

\begin{abstract}
Programme and resource management are two important factors to the successful implementation of projects in the construction industry. Historically, however, project resources are managed in isolation from the project programme, typically by accounting means. The shortcoming of this approach is they are not "activity based" and therefore only record the past performance and do not forecast the future, which is the essence of successful project management. This paper introduces two integrated programme and resource management models, which incorporate resource data from project databases into project programme to generate "activity based" and "quantifiable" outputs for the planning and monitoring of project time and resource.
\end{abstract}

\section{INTRODUCTION}

In recent years project managers have started using programming software such as Primavera Project Planner (P3) to integrate resource data into their programme in order to forecast resource requirements. The exercise is often restricted to the planning stage of a project due to the difficulties and expense associated with the updating methods that are built into the software package.

In this paper I shall introduce two specially designed resource databases, which are used in conjunction with the P3 programme to form integrated programme and resource management tools. The first is a Project Cost Database linked by ODBC (Open Database Connectivity - a protocol that enables a database to communicate with another external database electronically) to a Project Programme, which generates cashflow forecasts based on data obtained automatically from the cost database. The second is a Design Management Database, which records all relevant progress, and approval data during the design process, its outputs are linked to a design production S-curve, and also incorporated into a Design Programme to forecast weekly design resource requirements.

I shall then briefly review their relationship with other new Internet-related project management systems. Finally I will summarize the advantages and disadvantages of the two models introduced and associated issues, which potential users need to be aware of in their applications.

\section{INTEGRATED PROGRAMME AND COST CONTROL MODEL}

\subsection{Assumptions}

In Appendix 1 a major railway project is assumed, which has 120 cost centers with payment milestones built into a lump sum contract. The integrated programme and cost control model linking all payment milestones and the relevant budget into a Project Programme, will generate a baseline cashflow (budget ceiling). During the implementation stage of the project, time and cost data in the model are updated with actual progress, so that the actual cashflow and the s-curve can be checked against the baseline. The outputs are used not only to monitor cost performance, but also project progress. Any significant deviation between actual and budget cashflow at the project level is a clear indication of delay on programme, which calls for immediate attention from project managers.

\subsection{The Model And The Problem}

The model includes two parts; one is a Project Programme, which is developed in a programming software such as Primavera P3. The programme contains all the activities needed to achieve the milestones of all Cost Centers, which sets out the time element of project payment stream.

The second part of the model is a project Cost Database that contains, among other useful contents, 3 key elements 
A. Budgeted Cost - a series of Milestone Payments built into each cost center specified in the Contract, which form the baseline (ceiling) for each milestone;

B. Cost To Date - the accumulative actual cost to achieve a milestone at quarterly update;

C. Cost At Completion - the latest estimate of total cost for achieving a milestone.

Item C "Estimate At Completion" is to be monitored against Item A "Budgeted Cost". The aggregate variance for all cost centers between the two shows the predicted profit or loss of the whole project. When these three items are incorporated into corresponding activities in the project programme, quarterly cashflow and S-Curves can be generated showing past and forecast cost performance of the whole project at any particular period in time (as shown in Appendix1).

This model seems useful and straightforward, but it has so far rarely been used in the industry as a management tool in the implementation stage of a project. The reason is that while inputting of budgeted costs is a simple one-off exercise, because they do not normally change unless there is a variation to the Contract, when the project actually starts and the programme needs updated with actual cost data and the latest estimate above, the sheer size and frequency of update, as well as the clumsy arrangement for updating in the software makes it a difficult task.

\subsection{Automation of Programme Update from Project Cost Database}

In order to automate the process of updating the Programme with Cost To Date and Cost At Completion, we need to automatically link the Cost Database table with the cost table (*RES) within P3 database by ODBC. Every quarter when the Cost Database is updated with actual cost and latest estimate, an "Update Table" query is initiated to update the *RES table in P3 programme database automatically via ODBC, hence eliminating the painful manual updating process on cost data in P3. To establish the linkage we need to do the following:

- Assign each milestone payment item in the Cost Database table a unique ID which is to be linked to Activity IDs in the Programme;

- Set up an "Update Query" in the Cost Database by calling in the *RES table of the Programme database via ODBC, and then establish a "one-toone" linkage between the record ID of each milestone item within the Cost database and "ActID" of the *RES table from the Programme Database. Then design the query to update "CostToDate" and "CostAtCompletion" in the
*RES table with corresponding data from the Cost Database.

Each quarter the Database is updated on a cost center by cost center basis with, among many other useful data, latest actual and latest estimate cost figures, which will then be used to update the cost part of the Programme by initiating the "Update Query" in the Database in order to facilitate the generation of the cashflow table and S-Curve report from P3 as shown in Appendix 1.

\section{INTEGRATED DESIGN MANAGEMENT AND RESOURCE PLANNING MODEL}

\subsection{Key Issues}

Programme and resource management is particularly important in design management for design and build projects. First of all, design work has to be planned and managed effectively to suit the construction programme, and at the same time satisfy a fast-track design approval process from various stake holders such as the design checker, the works contractor, the Client, as well as relevant regulatory authorities. Secondly resource planning has to be integrated as part of the programme management so as to ensure a sufficient number and appropriate level of design staff are mobilized to deliver a specific element of drawings on time. Thirdly a proper change control system needs to be in place, so that design submissions, revisions and approvals are properly recorded and controlled.

\subsection{The Model}

a. Design Management Database

The model contains two parts, one is the Design Management Database which records all data relating to submission of drawings, including all target and actual dates of revisions and staged approvals for each design package, and automatically produces a weekly report as shown in Appendix 2. The database is also designed to count the number of drawings submitted each week and export such data for the production of weekly S-Curve in MS Excel as shown in Appendix 3. The chart gives an overview of how the whole design project is progressing at each design stage against target on a weekly basis. The data "Current Target" in the Chart is linked to the second part of the model, i.e. the Design Programme.

b. Design Programme

The Design Programme sets out the timing aspects of design approval process on a per 
design package basis as shown in Appendix 4. When the programme is updated and milestone dates for the approval of each design package shifted, the new dates are made available to the Design Management Database via ODBC link and used as "Current Target" for the production of S-Curve.

c. Resource Planning

When the Design Programme is regularly updated with latest progress data derived from the database, the programme can be used to forecast resource requirement for the period ahead. This is done by the following:-

- A man-hour budget for each drawing is assumed. This is calculated by dividing the total design budget of the project over the total number of drawings and then proportioned to different level of design staff according to their level of participation in each stage of design (e.g. DIR - Director, SE - Senior Engineer, E - Engineer, AE - Assistant Engineer, TO - Draftsman); it is shown as a budget template as below:- every month actual manhours spent on each design package are taken from Company's Timesheet Report and entered into the Design Program to generate actual vs. budget resource comparisons, tables and curves. They are used to validate the original assumptions (the budget template). If a significant deviation between the budget and the actual performance is identified, the template is calibrated accordingly in order to improve the accuracy of the future resource projections.

\section{UPDATING AND REPORTING VIA THE INTERNET}

In the last few years there have been a lot of web based construction project management tools coming to the market, such as ProjectNet (www.cephren.com), BidCom(www.bidcom.com) and Constructw@re (www.constructware.com). Most of them are designed for process control in document management, workflow management and/or

\begin{tabular}{|c|c|c|c|c|c|c|c|c|}
\hline \multirow[b]{2}{*}{ Activities } & \multicolumn{3}{|c|}{ BREAK DOWN OF TIME SPENT ON STAGES OF DESIGN } & \multicolumn{5}{|c|}{ Man-Hour Budgeted for Activities } \\
\hline & $\begin{array}{c}\text { Outline Design } \\
\text { Stage }\end{array}$ & $\begin{array}{c}\text { Detailed Design } \\
\text { Stage }\end{array}$ & $\begin{array}{c}\text { Checking } \\
\text { Stage }\end{array}$ & DIR & SE & $\mathrm{E}$ & $\mathrm{AE}$ & $\mathrm{TO} / \mathrm{DM}$ \\
\hline Outline Design Stage & & $\begin{array}{l}\text { Outline Design } \\
\text { Complete }\end{array}$ & \begin{tabular}{|l} 
Detailed \\
Design \\
Complete
\end{tabular} & 0.6 & 13.5 & 6.0 & 15.5 & 8.0 \\
\hline $\begin{array}{l}\text { Detailed Design } \\
\text { Stage }\end{array}$ & \multirow[t]{3}{*}{ (15\% of time) } & \multirow{3}{*}{ ( $75 \%$ of time) } & $\begin{array}{r}\text { Working } \\
\text { pDrawing }\end{array}$ & 0.6 & 9.0 & 6.0 & 22.5 & 12.0 \\
\hline \multirow[t]{2}{*}{ Checking Stage } & & & \multirow{2}{*}{$(10 \%$ of time $)$} & 0.3 & 11.3 & 3.0 & 15.5 & 8.0 \\
\hline & & & & & & & & \\
\hline & & & TOTAL: & 1.5 & 33.8 & 15.0 & 53.5 & 28.0 \\
\hline
\end{tabular}

- the budget template is then applied to each design package where the man-hour budget is multiplied by the number of drawings in the Design Management Database, they then form the basis of budgeted resource for each design package and incorporated into the Design Programme to generate overall weekly man-hour tables and histograms for each category of staff as shown in Appendix 5;

if the histogram shows that in any future period the required man-hour of a certain category design staff seriously exceeds the current level of resource committed, additional staff need to be mobilized to fill the gap, or some design packages have to be delayed. A detailed analysis of the resource table is needed to identify the design packages that cause the resource overrun and which design packages can be delayed; collaborative tracking, which are focused on collective participation within a team.

The models we have introduced here, however, are more focused on programme and cost control on a centralized project management level, which require less high tech software. The two models are both developed by peripheral software using Primavera P3 and MS Access. P3 has Internet reporting capability, which enables a project programme to be viewed from the web. It is very rare, however, for a project programme to be published on the web due to its contractual sensitivity and security concerns. Remote updating to the Project Cost Database and Design Management Database could be useful when ASP capability (Active Server Pages) in MS Access is fully provided. In model 1 different contractors in the project will then be able to update their respective cost centers with actual and latest estimate of cost from their own office. In model 2, actual design submission dates will be updated by individual design teams within the design organisation. 
It is arguable, however, whether such remote access should be provided to anyone other than the project controller. Past experience shows that project managers prefer to restrict access to these databases to only a few members of staff, who are made responsible not only for updating and maintaining the database, but also for checking and validating the data they receive from various sources, usually by email or by transmittals. As part of a change control system, it seems to be a sensible approach.

\section{CONCLUSIONS}

There are plenty of peripheral software tools on the market for project programme and resource control. These tools, however, need to be customized to produce quantifiable means of evaluating progress on time and resources. The integration of project resources into a programme makes it possible for budgeted and actual resources, whether in dollar or in man-day terms, to be broken down into manageable period, such as every month, based on relevant activities.

In model 1, we suggested that an electronic linkage between a Project Cost Database and the resource table in a project programme can make the programme a powerful "activity based" cost control tool. It eliminates the problem of manual updating resource data in the programme and, hence automates the process of producing activity based monthly or quarterly cashflow report.

In model 2 we come up with a Design Management Database, which generates drawing production reports by recording and counting number of drawings targeted and actually delivered on a weekly basis. The target delivery dates for each design package are linked to the Design Programme, which is in turn determined by the main construction programme in a design and build project. The integration also occurs when records of drawing production in the database are used to validate and audit progress shown in Design Programme for each design package basis.

It is worth noting that in both models the databases are not developed purely for incorporating resource data into the project programme. Any major construction project should have a centralized cost database to maintain a full record of cost performance during implementation of the project. Likewise any design project, particularly in a design and build project should have a design management database to record and report details of design submissions including such items as RFIs (Request for Information, FCRs (Field Change Request), DIs (Designer Instruction) etc. for change control purposes. Their integration into the programme merely makes them more powerful tools as part of the management system.

Like many other planning tools, however, these two models have their limitations. The time and effort involved in setting up the models at the start of a project mean that they provide real value only on major projects. In model 1, for instance, cashflow from any particular cost center may contain errors and therefore appear meaningless, and it is only on project level on a major project that these errors will be balanced out when all data from a large number of cost centers are rolled up in the aggregated project level report. The model was first developed for one of our feasibility study projects in Hong Kong, which involved 71 work packages with total project sum of HK $\$ 35$ billion.

Similarly model 2 was initially developed and applied in one of our major design and build projects in Hong Kong, which involved preparation of 1200 design drawings. Although the assumed resource budget template per drawing was regularly reviewed and calibrated for accuracy, and was found reasonably close to reality, it is probably still applicable only to similar sized projects under similar circumstances.

Nevertheless, our experiences show that there is a real need for the tools that we have described above in the management of major projects. At strategic level, managers need to be regularly briefed with latest update of overall programme and resource performance in the project. It is not only the reports themselves that are useful, but the process to collect and roll up the detailed performance indicators to the top level helps to reinforce a disciplined approach in project reporting and control. Furthermore, the analysis produced in the models, such as the detailed design resource budget and actual expenditure analysis, will not only benefit the current project, but be used as valuable reference for the biding and managing of future jobs. 
Appendix 1 - Integrated Programme/Resource Management System

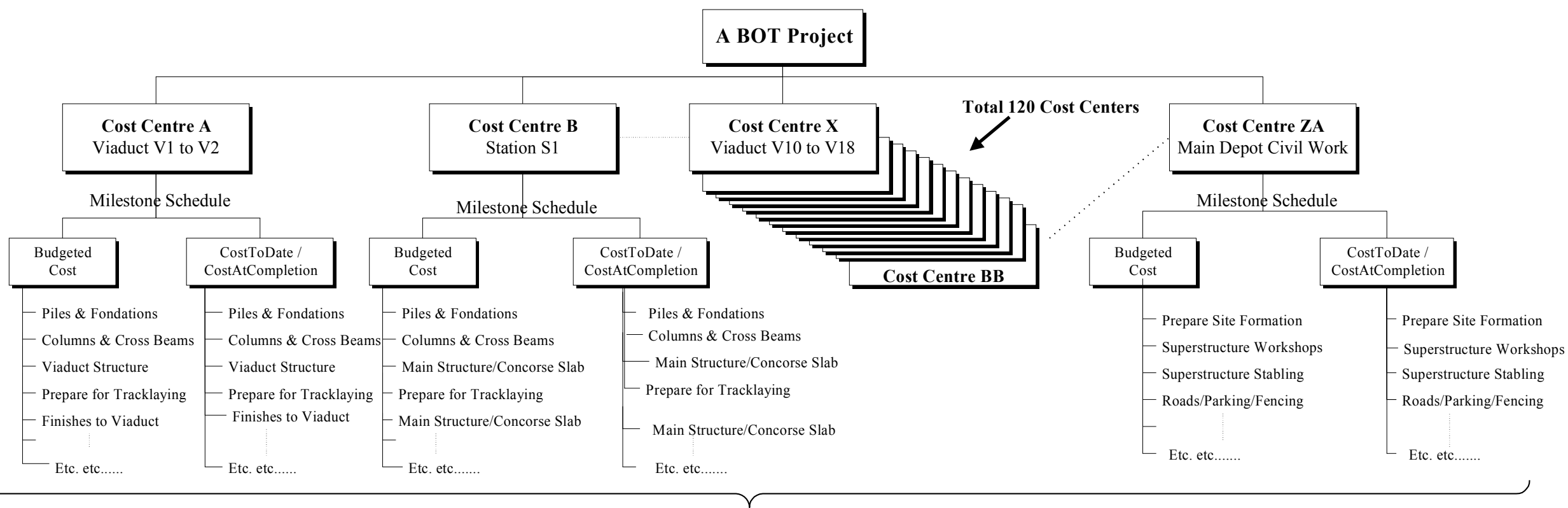

Cost data from Project Cost Database automatically fed through to Project Programme via Open Database Connectivity (ODBC)

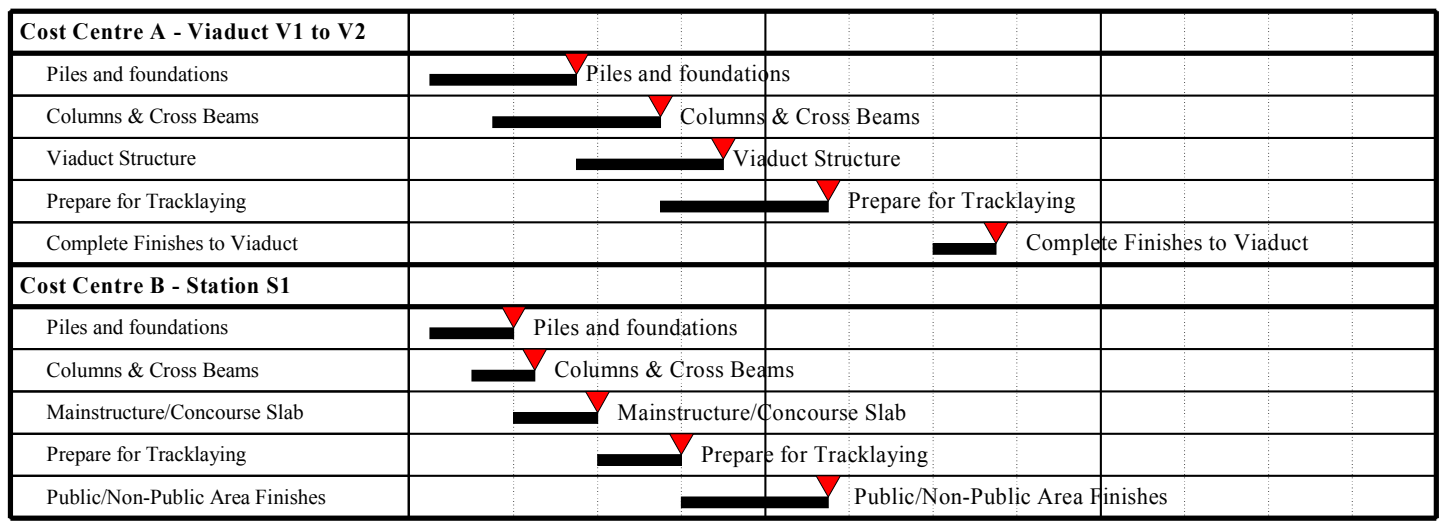

\begin{tabular}{|c|c|c|c|c|c|c|c|c|c|c|c|c|}
\hline \multirow[b]{2}{*}{ Cost Centre A } & \multicolumn{4}{|c|}{$2002 / 03$} & \multicolumn{4}{|c|}{$2003 / 04$} & \multicolumn{4}{|c|}{$2004 / 05$} \\
\hline & $\mathrm{Q1}$ & $\mathrm{Q} 2$ & Q3 & $\mathrm{Q} 4$ & Q1 & $\mathrm{Q} 2$ & $\mathrm{Q} 3$ & $\mathrm{Q} 4$ & $\mathrm{Q1}$ & $\mathrm{Q} 2$ & $\mathrm{Q} 4$ & $\mathrm{Q} 4$ \\
\hline Original Bugete & 30.0 & 20.0 & 15.0 & 40.0 & 60.0 & 18.0 & 45.0 & 25.0 & 15.0 & 100.0 & 120.0 & 30.0 \\
\hline Latest Estimate & 40.0 & 10.0 & 10.0 & 25.0 & 50.0 & 15.0 & 50.0 & 30.0 & 20.0 & 110.0 & 110.0 & 50.0 \\
\hline Actual To Date & 40.0 & 10.0 & 10.0 & & & & & & & & & \\
\hline
\end{tabular}

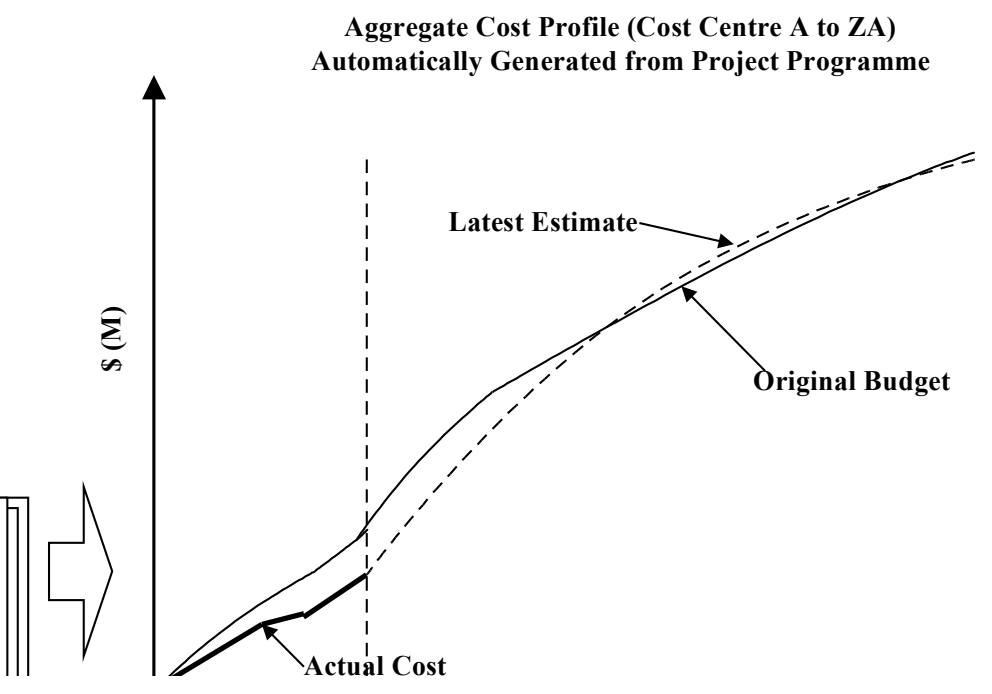




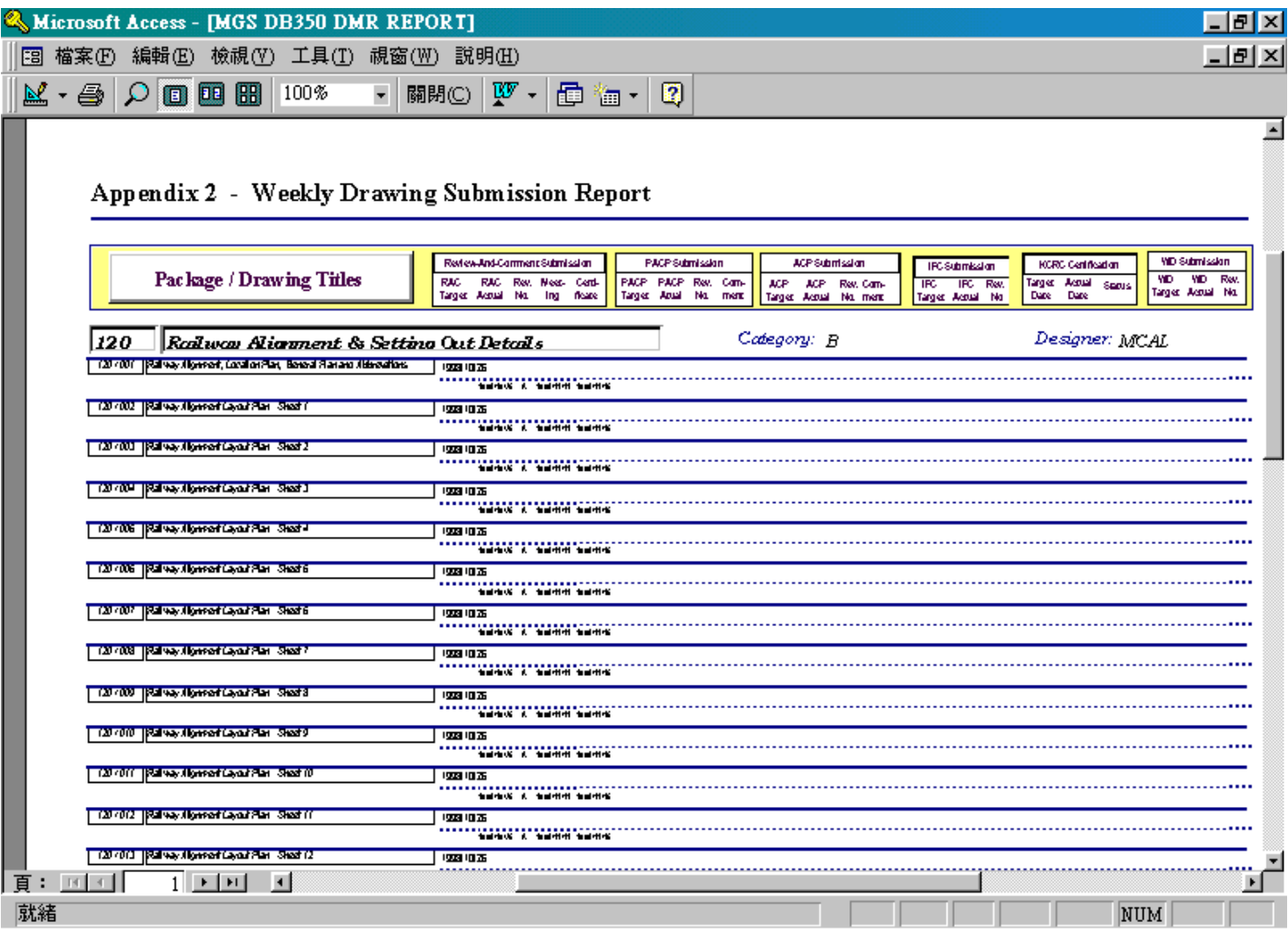

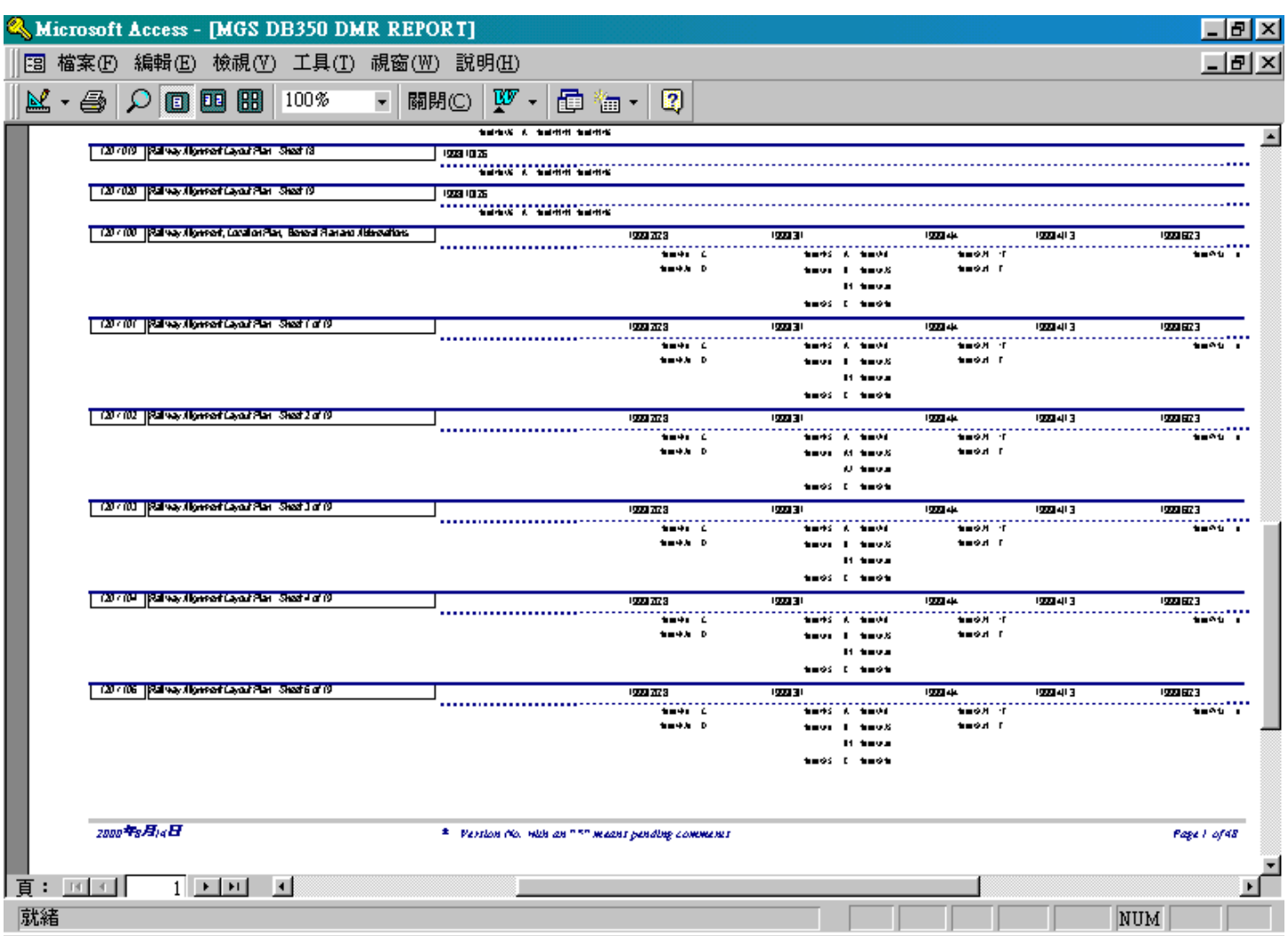




\section{[2 Microsoft Excel - MGS-mit2}

$-\left[\begin{array}{l|l|}\hline-a \\ \hline\end{array}\right.$

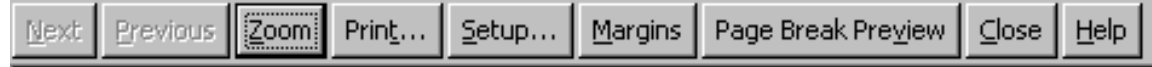

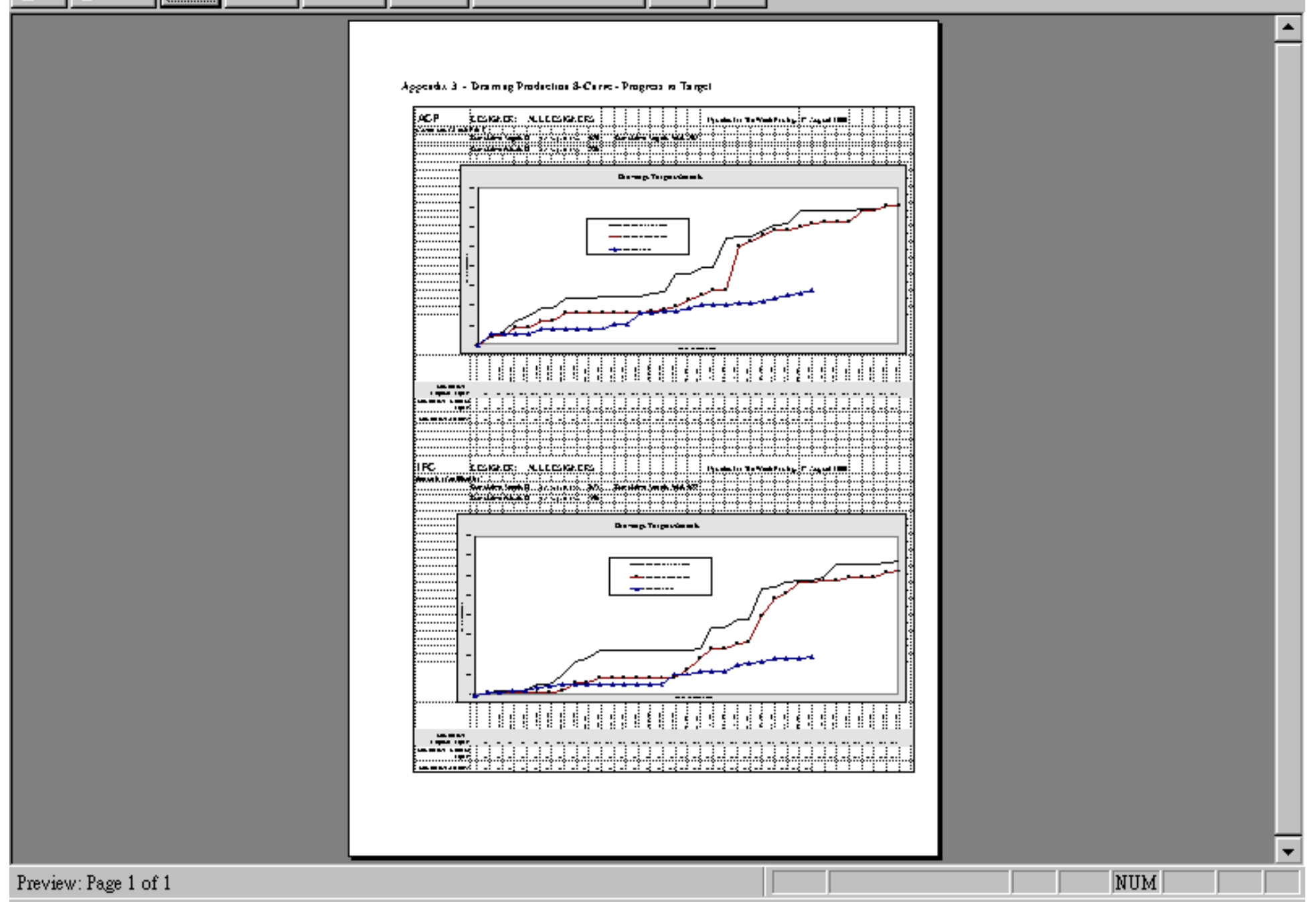




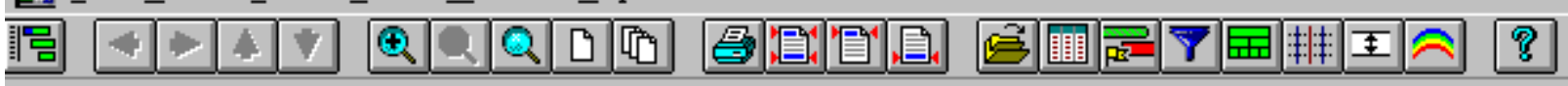

Appendix 4 - Design Programme (One Design Package for Sample Only)

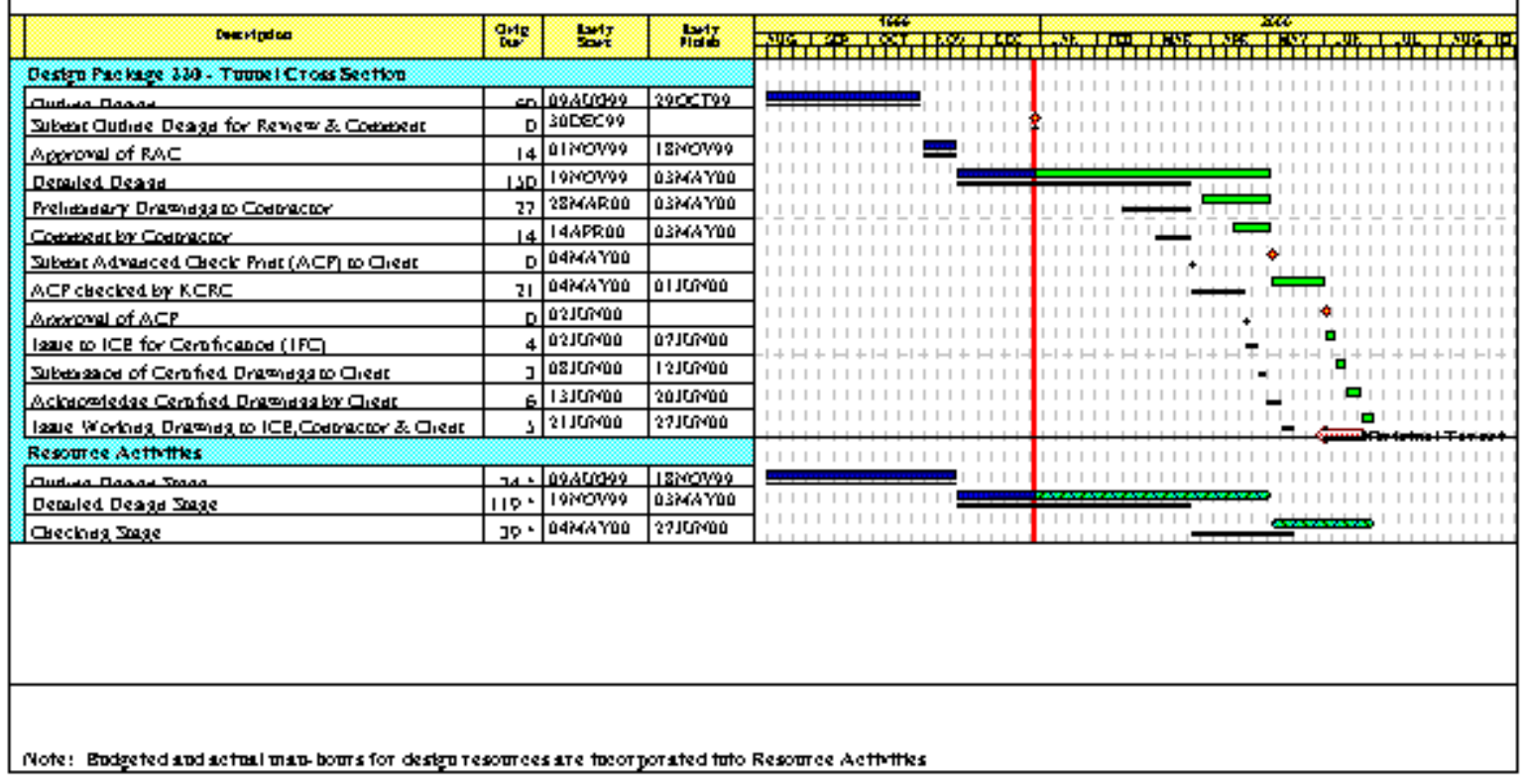


Appendix 5 - Monthly Design Resource Requirement

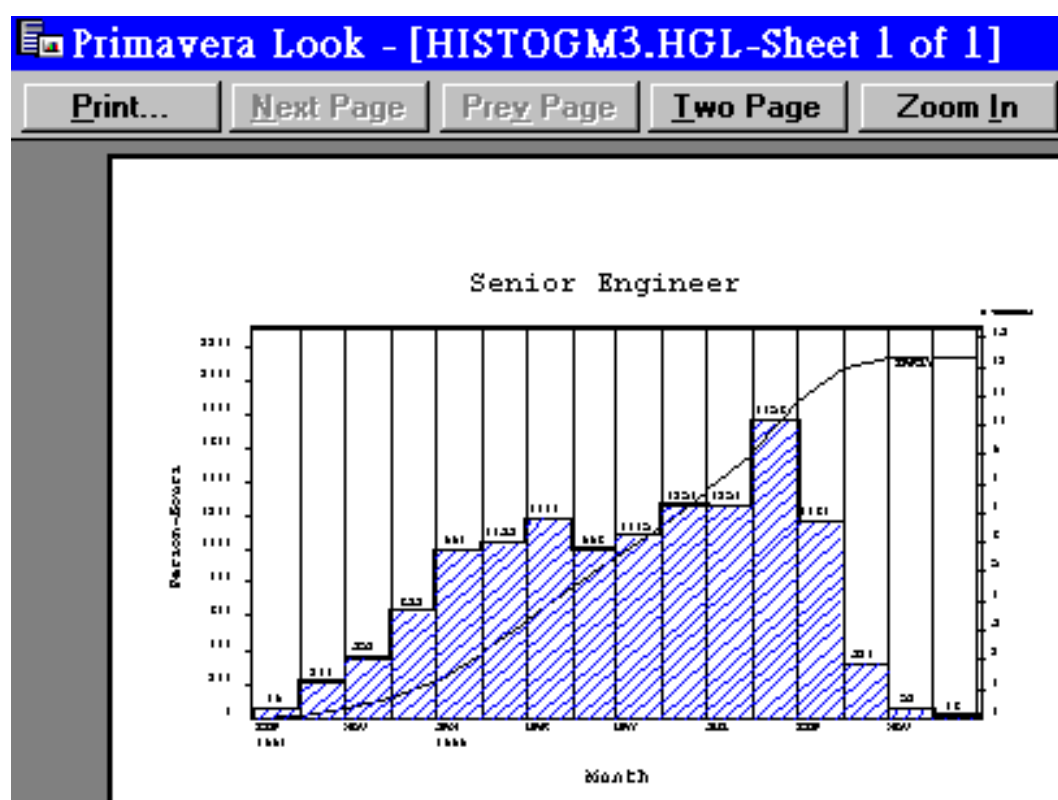

$-\left[\begin{array}{l|l|}\hline \\ \hline\end{array}\right.$
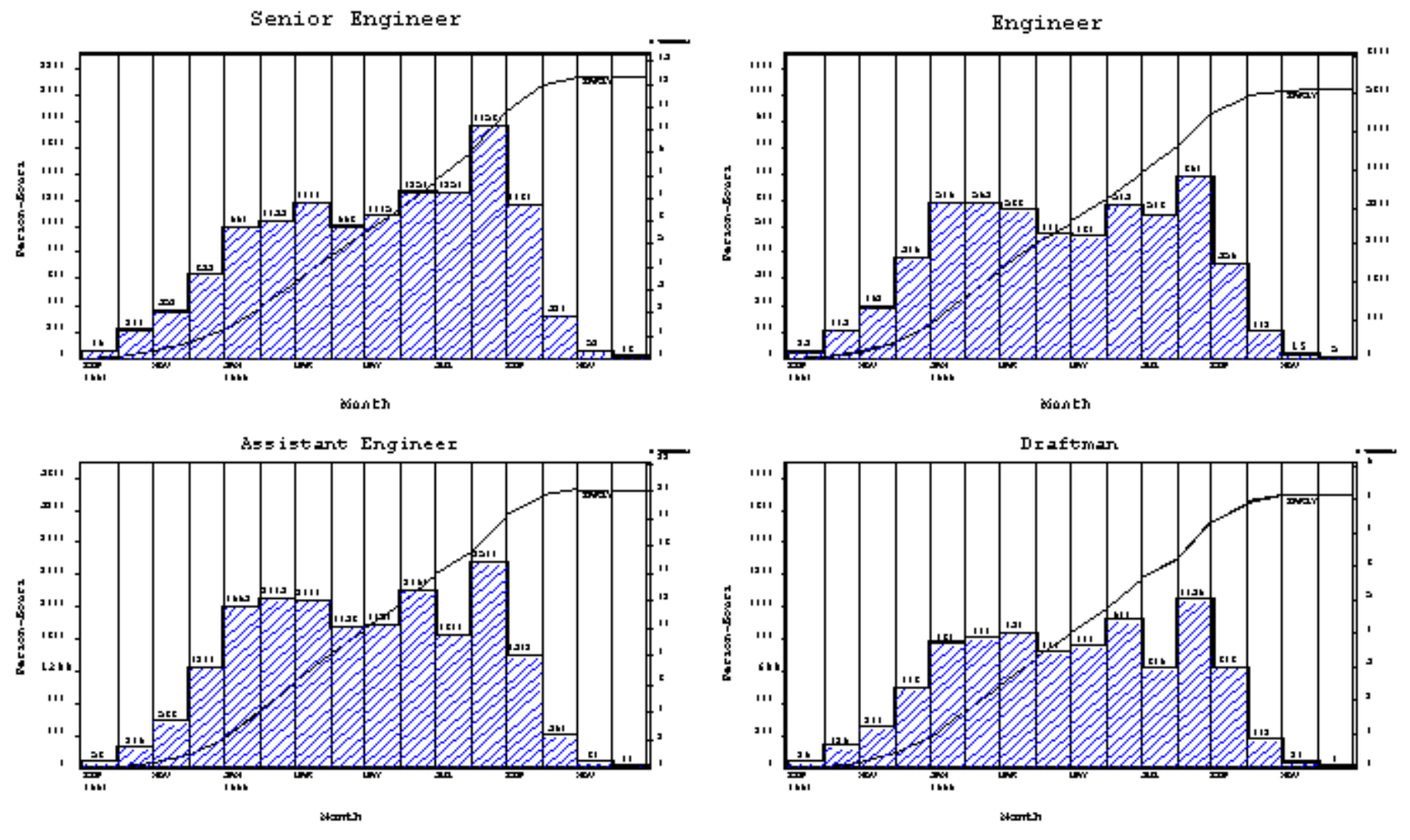